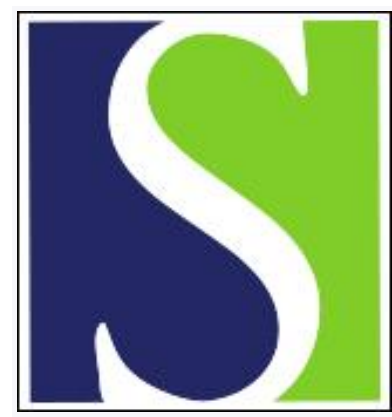

Scand J Work Environ Health 2020;46(6):630-638

https://doi.org/10.5271/sjweh.3901

Published online: 17 May 2020, Issue date: 01 Nov 2020

Quality improvement activity in occupational healthcare associated with reduced need for disability retirement: A Bayesian mixed effects modelling study in Finland

by Kuronen J, Winell K, Kopra J, Räsänen K

Being affiliated with the occupational healthcare (OHC) quality network (OQN) - a voluntary collaborative forum in Finland - can reduce the need for disability pensions among employees in the care of the $\mathrm{OHC}$ unit. When the $\mathrm{OHC}$ unit participates in common quality improvement (QI) activities (quality measurements of intervening in excess use of alcohol, quality facilitator training, and the focus of work ability measurements) it may decrease the risk of work disability pensions.

Affiliation: Etelä-Savon Työterveys Oy, Maaherrankatu 13, 50100 Mikkeli, Finland. jarmo.kuronen@fimnet.fi

Refers to the following texts of the Journal: 2012;38(6):516-526 2017;43(5):447-456 2018;44(2):134-146 2019;45(2):203-208

Key terms: alcohol; Bayesian mixed effects modelling; depression; disability; disability pension; disability retirement; Finland; health check-up; networking; occupational healthcare; pension; quality improvement; retirement; work ability

This article in PubMed: www.ncbi.nlm.nih.gov/pubmed/33135767 


\title{
Quality improvement activity in occupational healthcare associated with reduced need for disability retirement: A Bayesian mixed effects modelling study in Finland
}

\author{
by Jarmo Kuronen, MD, ${ }^{1}$ Klas Winell, PhD, ${ }^{2}$ Juho Kopra, PhD, ${ }^{2,3}$ Kimmo Räsänen, PhD ${ }^{4}$
}

\begin{abstract}
Kuronen J, Winell K, Kopra J, Räsänen K. Quality improvement activity in occupational healthcare associated with reduced need for disability retirement: A Bayesian mixed effects modelling study in Finland. Scand J Work Environ Health. 2020;46(6):630-638. doi:10.5271/sjweh.3901
\end{abstract}

Objectives There is evidence that occupational healthcare (OHC) may improve employees' work ability. This research was designed to study whether common quality improvement (QI) activities in the OHC quality network $(\mathrm{OQN})$ - a voluntary collaborative forum - can reduce the need for disability pensions.

Methods The study population comprised employees under the care of $19 \mathrm{OHC}$ units in Finland affiliated with the OQN. The association of 12 QI activities with new disability pensions during the years 2011-2017 was analyzed by Bayesian mixed effects modelling.

Results Patients of $\mathrm{OHC}$ units affiliated with the OQN have fewer full permanent disability pensions [odds ratio (OR) $0.77,95 \%$ credible interval (CI) $0.60-0.98$ ] and full provisional disability pensions (OR $0.68,95 \%$ CI 0.53-0.87) than patients of unaffiliated units. Of the studied QI activities, the measurements of intervening in excessive use of alcohol had the strongest association with the incidence of all disability pensions (OR 0.53, $95 \%$ CI $0.41-0.68)$. Participation in the focus of work measurements and quality facilitator training was also associated with the reduced incidence of disability pensions (OR $0.84,95 \% \mathrm{CI} 0.71-0.98$, and OR $0.92,95 \mathrm{CI}$ 0.84-0.99, respectively).

Conclusions Affiliation with a quality network seemed to improve outcomes by reducing full disability pensions or replacing them by partial disability pensions. Some QI activities in the OQN were associated with a reduction of disability pensions.

Key terms alcohol; depression; disability pension; health check-up; networking; pension; work ability.

Efforts are underway globally to improve the quality, coverage and security of healthcare (1). Quality improvement (QI) initiatives in healthcare aim at enhancing service delivery through process development (2). Such initiatives include activities that strive to improve existing processes or redesign processes altogether (2-4). Occupational healthcare $(\mathrm{OHC})$ should focus on its core tasks, which are the promotion of healthy workplaces (5) and ensuring the health and work ability of employees $(6,7)$.

Processes intended to enhance and maintain employees' work ability should be established on evidencebased methods. Initiatives designed to reduce the risk of work-related disability can be particularly effective. These include general job modification, return-to-work coordination and organizational support (5), and targeted health check-ups for employees with work incapacities, followed by health-focused and workplace interventions addressing cases of musculoskeletal and mental disorders $(8,9)$. Reorganization of $\mathrm{OHC}$ services, including service coordination and rehabilitation after injuries, has been shown to reduce disability pensions (10). Multidomain interventions in the workplace including work adjustments, changes of role or work tasks, reductions in working hours, sabbaticals, physiotherapy and physical exercise may reduce the likelihood of disability pension

1 Orchid ID 0000-0001-8929-070X; Etelä-Savon Työterveys Oy, Mikkeli, Finland.

2 Conmedic Oy, Espoo, Finland.

3 Etelä-Savon Työterveys Oy, Faculty of Health Sciences, School of Medicine, Institute of Clinical Medicine, Kuopio Musculoskeletal Research Unit, Kuopio, Finland.

4 University of Eastern Finland, Faculty of Health Sciences, School of Medicine, Institute of Public Health and Clinical Nutrition, Kuopio, Finland. 
(11). Early vocational rehabilitation can have the same effect (12). While depression is one of the main global reasons for disability, in Finland improvement and better organization of care are required before disability pension is granted due to depression $(13,14)$.

Disability retirement is predominantly caused by mental and musculoskeletal disorders (15). Other causes include cardiovascular diseases and accidents (15). Due to the ageing of the labor force (16), a lot of emphasis is put on the promotion of work participation and avoidance of early retirement (17). Predictive risk estimates have been developed for the prevention of chronic conditions (18). Once preventive activities have been implemented in $\mathrm{OHC}$ it can take a long time, even decades, for effects to be seen $(19,20)$. This means that outcome measures often cannot be used, thus process performance indicators are preferred in improvement measurements (19).

Often the results of $\mathrm{OHC}$ are assessed only by the resources employed and the number of patient visits because these are easy to measure. Instead, we should strive to measure the processes and their outcomes (eg, the reduction in the disability retirement). Measuring the performance of a process is more demanding and expensive than measuring the number of patient visits $(2,21)$ but gives more evidence of its effectiveness $(4)$. Data on the performance of healthcare processes can be used to improve both the organization of care and clinical decision-making (22).

In addition to the evidence that $\mathrm{OHC}$ may improve the prevention of disabilities $(8,23)$ there is also evidence that networking may improve the quality and outcomes of healthcare, although this has not been studied in the field of OHC (24).

One of the major shared goals of employers, employees and $\mathrm{OHC}$ is the reduction of early retirement due to disability. Although much has been written about QI in healthcare, little is known about its impact in $\mathrm{OHC}$ on disability retirement. Therefore, we designed a study to find out whether the implementation of common QI activities in the occupational healthcare quality network $(\mathrm{OQN})-\mathrm{a}$ voluntary collaborative forum consisting of $\mathrm{OHC}$ service providers - reduces the need for disability retirement and which specific activities affect the outcomes. The study hypothesis was that common QI activities in the OQN are effective in reducing disability pensions.

\section{Methods}

\section{The occupational healthcare quality network}

At its foundation in 2011, the Finnish OQN had two goals: to reduce the rate of disability retirement, espe- cially the full permanent disability pension, and lower the number of full disability pensions in favor of partial pensions. Conmedic, a nonprofit company that coordinates healthcare quality networks and facilitates the OQN, performed the data analyses of quality measurements. The members of the OQN support each other's development by exchanging material and information on best practices. Each $\mathrm{OHC}$ unit consists of occupational health physicians, occupational nurses, occupational physiotherapists and occupational psychologists. Since the foundation of the OQN, each unit has performed several of the common QI activities. The member units of the OQN have used the continuous quality development model in the development of processes (25) with repeated measurements of process indicators. This study included activity data from $19 \mathrm{OHC}$ units across Finland that have been affiliated with the OQN either through the whole study period or for only a few years.

\section{The study population and data}

The outcome data covered the disability pensions of all Finnish municipality employees during 2005-2017 obtained from the pension registers of Keva, the largest pension provider in Finland which administers the pensions of public sector workers. The clients of the $\mathrm{OHC}$ units (municipalities) had to agree to the retrieval of data on disability retirements among their employees from Keva records. All the data from Keva were aggregated and anonymous with no possibility for an individual's identification.

The activity data were collected from January 2011 to December 2017, during which time the subset of OHC units affiliated with the OQN has varied. Regardless, the activity data of all participants was collected.

The study population consisted of all employees in the care of the 19 OHC units affiliated with the OQN between 2011 and 2017. The comparison population were all municipality employees in the care of nonaffiliated $\mathrm{OHC}$ units. The annual number of employees in the study population ranged between 32 239-38 438 and $445628-487921$ in the comparison population during the period 2005-2017.

The 12 QI activities analyzed were: participation in (i) measurements of intervening in excessive use of alcohol; (ii) quality measurements of health check-ups; (iii) quality facilitator training; (iv) focus of work measurements; (v) resource measurements; (vi) quality network workshops; (vii) peer review training; (viii) quality measurements of depression care; (ix) advisory board of the OQN; (x) employee and employer satisfaction surveys; and reporting of (xi) QI plans for the coming year; and (xii) QI activities.

The focus of work measurements included measuring the following indicators in registers: proportion 
of the work done in preventive healthcare (following the classification of the National Pension Institution), proportion of all contacts directed to employees with musculoskeletal or mental disorders (which are the main reasons for early retirement), and the number of tripartite negotiations (employee with reduced work ability, employer and $\mathrm{OHC}$ ) per year. The QI activities with their descriptions are presented in table 1.

We used the incidence of different disability pensions as outcome measures for the effects of QI activity in the OQN. The incident disability retirement was calculated by dividing the number of granted disability pensions by the number of insured employees at the end of each year. The definitions of the different pension benefits are described in table 2. We followed the STROBE guideline in the set-up of the study.

\section{Statistical analysis}

The statistical analysis was run by using a Bayesian generalized linear mixed model consisting of both fixed and random effects (26). The mixed-effect approach was chosen because it allows the modelling of employerspecific variability and yearly variability of data, thus rendering estimates that are representative of the overall effect of each fixed effect covariate of interest.
As there was no separate reference group to compare the activity data with, the units not affiliated with the OQN each year were used in the statistical model to estimate the effect of the covariates to the outcome. The random effects take care of adjusting for yearly variability as well as OHC-unit-specific variability, so that the fixed-effects estimates represent the overall effect of the study population.

Credible intervals (a Bayesian analogy to confidence intervals) are reported. Readers with no Bayesian background can follow the results in table 3 by interpreting the $95 \%$ credible intervals $(95 \% \mathrm{CI})$ similarly as confidence intervals for odds ratios (OR).

The Bayesian model was implemented using Just Another Gibbs Sampler (JAGS) software (27) and data preprocessing was done in $\mathrm{R}$ (28). Each model was fitted to the data using four Markov Chain Monte Carlo (MCMC) chains (29) with a total length of 500000 iterations. The first 20000 iterations were discarded as a burnin. Thinning to every 100 iterations were used leading to 19200 iterations stored for each model. The MCMC chains appear to have converged based on both visual inspection and Brooks-Gelman-Rubin Rhat-diagnostics (30). The Rhat-values were $<1.006$ for all covariates in the model. The Rhat-value 1.00 indicates the perfect convergence and all values $<1.05$ are acceptable.

Table 1. Definition of affiliation with the Finnish Occupational Health Quality Network (OQN) and the 12 quality improvement activities. [OHC=0ccupational healthcare.]

\begin{tabular}{|c|c|}
\hline Quality improvement activity of the OQN & Definition \\
\hline Affiliation with the $0 Q N$ & $\begin{array}{l}\text { The OHC units that have been affiliated with the OQN either through the whole study period or only a few (2-4) } \\
\text { years. }\end{array}$ \\
\hline $\begin{array}{l}\text { Participation in measurements of intervening in } \\
\text { excessive use of alcohol }\end{array}$ & $\begin{array}{l}\text { Number of times the } \mathrm{OHC} \text { unit has participated in the quality measurement of performing a brief intervention } \\
\text { with employees who have excessive use of alcohol. Yearly } 2 \text {-day measurement has been performed three times. } \\
\text { The measurement with } 17 \text { indicators directs to all consultations in the } \mathrm{OHC} \text {. }\end{array}$ \\
\hline $\begin{array}{l}\text { Participation in health check-up quality } \\
\text { measurements }\end{array}$ & $\begin{array}{l}\text { Number of times the } \mathrm{OHC} \text { unit has participated in the yearly quality measurement of health check-ups. Consists } \\
\text { of all consecutive health check-ups targeted to employees with reduced working capacity or hazardous work } \\
\text { (31 indicators) and performed by any of the professionals in the } \mathrm{OHC} \text { unit (OHC physician, } \mathrm{OHC} \text { nurse, } \mathrm{OHC} \\
\text { physiotherapist or } \mathrm{OHC} \text { psychologist) during a 2-4 week time (depending on the size of the OHC unit). }\end{array}$ \\
\hline Participation in quality facilitator training & $\begin{array}{l}\text { Number of persons that have participated in the training. The training consists of three 2-day educational ses- } \\
\text { sions with development tasks in the own } \mathrm{OHC} \text { unit between the sessions. }\end{array}$ \\
\hline Participation in focus of work measurements & $\begin{array}{l}\text { Number of times the } \mathrm{OHC} \text { unit has participated in the yearly focus of work measurement. The measurement } \\
\text { consists of patient flow and billing data of the } \mathrm{OHC} \text { unit ( } 6 \text { indicators of proportion of preventive work, propor- } \\
\text { tion of consultations directed to employees with musculoskeletal or mental problems and number of three } \\
\text { party negotiations with employee with reduced work ability, employer and } \mathrm{OHC} \text { ). }\end{array}$ \\
\hline Participation in resource measurements & $\begin{array}{l}\text { Number of times the } \mathrm{OHC} \text { unit has participated in the yearly resource measurement which consists of person- } \\
\text { nel structure and finances of the } \mathrm{OHC} \text { unit (14 indicators). }\end{array}$ \\
\hline Participation in quality network workshops & $\begin{array}{l}\text { Number of persons, who have participated in the workshops, which consist of two or three educational days } \\
\text { per year. }\end{array}$ \\
\hline Participation in peer review training & $\begin{array}{l}\text { Number of persons who have participated in the training which consists of coaching the } \mathrm{OHC} \text { team to run a } \\
\text { structured peer review, perform one and be target for one. }\end{array}$ \\
\hline $\begin{array}{l}\text { Participation in quality measurements of } \\
\text { depression care }\end{array}$ & $\begin{array}{l}\text { Number of times the } \mathrm{OHC} \text { unit has participated in the yearly quality measurement of depression care. The mea- } \\
\text { surement consists of } 50 \text { or more previous patients diagnosed with depression ( } 35 \text { indicators). }\end{array}$ \\
\hline Participation in advisory board of the $0 Q N$ & $\begin{array}{l}\text { Number of times the leaders of the } \mathrm{OHC} \text { unit have participated in the board meetings. The advisory board } \\
\text { meets once a year to determine the activities of the OQN for the incoming year. }\end{array}$ \\
\hline $\begin{array}{l}\text { Participation in employee and employer } \\
\text { satisfaction surveys }\end{array}$ & $\begin{array}{l}\text { Number of times the } \mathrm{OHC} \text { unit has participated in the yearly satisfaction measurement of employees and em- } \\
\text { ployers. The measurement consists of questionnaires to all client companies of the } \mathrm{OHC} \text { unit (50 indicators). }\end{array}$ \\
\hline $\begin{array}{l}\text { Reporting the quality improvement plans for the } \\
\text { coming year }\end{array}$ & $\begin{array}{l}\text { Number of times the } \mathrm{OHC} \text { unit has announced the improvement plans. Consists of the main activities to come } \\
\text { of the } \mathrm{OHC} \text { unit. }\end{array}$ \\
\hline Reporting quality improvement activities & $\begin{array}{l}\text { Number of times the } \mathrm{OHC} \text { unit has participated in the yearly reporting. The report consists of all quality im- } \\
\text { provement activities performed during the previous year. }\end{array}$ \\
\hline
\end{tabular}


Table 2. Definitions of outcomes.

\begin{tabular}{ll}
\hline Outcome indicator & Definition \\
\hline $\begin{array}{l}\text { Full permanent } \\
\text { disability pension }\end{array}$ & $\begin{array}{l}\text { An individual must have a permanent reduction in } \\
\text { the work capacity of over } 60 \% .\end{array}$ \\
$\begin{array}{l}\text { Partial permanent } \\
\text { disability pension }\end{array}$ & $\begin{array}{l}\text { An individual must have a permanent reduction in } \\
\text { the work capacity of } 40-60 \% .\end{array}$ \\
$\begin{array}{l}\text { Full provisional } \\
\text { disability pension }\end{array}$ & $\begin{array}{l}\text { An individual must have a temporary reduction of } \\
\text { the work capacity over } 60 \% \text {. Usually granted for no } \\
\text { more than one year during which time the person is } \\
\text { rehabilitated. }\end{array}$ \\
$\begin{array}{l}\text { Partial provisional } \\
\text { disability pension }\end{array}$ & $\begin{array}{l}\text { the work capacity of } 40-60 \% \text {. Usually granted for no } \\
\text { more than one year during which time the person is } \\
\text { rehabilitated. }\end{array}$ \\
\hline
\end{tabular}

Description of the model. The data has $N$ observations where the index $i$ runs over the rows of data. The response $y_{i}=\left(k_{i}, n_{i}\right)$ consists of the number of disability retirements $k_{i}$ and number of employees $n_{i}$ in OHC care during the year at row $i$. In addition, we utilized the 12 QI activities as indicators of participation in the OQN. We included the covariate "Affiliation with the Finnish Occupational Healthcare Quality Network", which indicates whether the OHC Emp(i) participated in any QI activity during Year(i), which also defines it as being affiliated with the OQN.

We generated five different models (marked \#), each with different response covariates, but all within the same modelling setting. For each model, the response $y_{i} \sim$ Binom $\left(p_{i}, k_{i}\right)$ stands for \#1 Full permanent disability pension, \#2 Partial permanent disability pension, \#3 Full provisional disability pension, \#4 Partial provisional disability pension or $\# 5$ All granted disability pensions.

The probability $P\left(y_{i}=1\right)=p_{i}$ of obtaining a disability retirement was modeled by the following equation:

$\log \left(p_{i} /\left(1-p_{i}\right)\right)=\beta_{0}+b_{E m p}[\operatorname{Emp}(i)]+b_{\text {Year }}[$ Year $(i)]+($ fixed effects $)$

In this equation, the parameter $\beta_{0}$ is a constant that defines the base level for retirement. Parameters $b_{E m p}$ and $b_{\text {Year }}$ are random effects for employer and calendar year, and the term fixed effects depends on the model. The presence of the random effect term $b_{E m p}[\operatorname{Emp}(i)]$ factors in this model means that the measurements from the same employers in different years are more similar to each other than to those measured among the other employers. Respectively, $b_{\text {Year }}[$ Year $(i)]$ factor is the year-dependent effect of different years. The random effect terms follow Gaussian distribution:

$$
b_{E m p}[s] \sim N\left(0, \sigma_{E m p}^{2}\right), s=1, \ldots, N_{E m p}
$$

and

$$
b_{\text {Year }}[t] \sim N\left(0, \sigma_{\text {Year }}^{2}\right), t=1, \ldots, N_{\text {Year }}
$$

Prior probability distributions. The prior probability distributions, which represent information regarding model parameters available prior to the analysis were as follows: For the constant and each fixed effect parameter, the $N(0,1000)$ was used. For the variance parameters $\sigma_{E m p}^{2}$ and $\sigma_{\text {Year }}^{2}$ of the random effects $b_{E m p}[s], s=1, \ldots, N_{E m p}$ and $b_{\text {Year }}[s], s=1, \ldots, N_{\text {Year }}$, the inverse gamma distribution with parameters 0.001 and 0.001 was used.

Model selection. The models were selected according to the deviance information criteria (DIC) (31). After the model selection phase, each of the selected five models had a different number of covariates remaining. The model coefficients are transformed to OR using $O R=$ $\exp (\beta)$ where $\beta$ stands for fixed effect. The OR for fixed effects of all models are reported in table 3 . Where a numerical value is not given (ns) the independent covariate has been excluded from the final model due to model selection. For example, in the model of "Full permanent disability pension", the only remaining fixed effects are affiliation with the Finnish OQN and participation in resource measurements.

\section{Results}

The mean age of the employees who were granted a disability pension in 2017 was 55.1 years in the study population while it was 54.1 years among all municipality employees. The number of different disability pension types granted during 2011-2017 are shown in figure 1 . The number of full permanent disability pensions decreased from 31.7 grants $/ 10000$ employees in 2011 to 13.6 grants /10 000 employees in 2017, while partial permanent disability pension and partial provisional disability pensions had a slightly increasing trend. The number of provisional pensions granted fluctuated during the period and peaked in 2008 .

The affiliation of OHC units with the OQN is associated with a reduction in full disability pensions compared to the unaffiliated units, OR for full permanent disability pension $0.77,95 \%$ CI $0.60-0.98$ and for full provisional disability pension $0.68,95 \%$ CI $0.53-0.87$ (table 3). For all disability pensions, the association was not as strong as it was with full permanent disability pensions (OR 0.86, 95\% CI 0.72-1.03).

Some of the QI activities appeared to be especially valuable in reducing disability retirement. Participation in the quality measurements of intervening in excessive use of alcohol was strongly associated with the reduction of all disability pensions (OR $0.53,95 \% \mathrm{CI}$ 0.41-0.68). The association with the partial permanent disability pensions was even stronger (OR $0.35,95 \% \mathrm{CI}$ $0.22-0.55)$. Participation in the quality measurements 
of health check-ups (HCU) was associated with the reduction of all disability pensions (OR $0.87,95 \% \mathrm{CI}$ $0.75-1.0)$. The association was especially strong with both types of partial disability pensions. Participation in the focus of work measurements associated also positively with the reduced incidence of total disability retirement (OR 0.84, 95\% CI 0.71-0.98) as did participation in the quality facilitator training (OR $0.92,95 \%$ CI 0.84-0.99) (table 3).

Some QI activities had negative associations with the reduction of incidence in disability pensions. Participation in the quality measurements of depression care was associated with an increased risk of total granted disability pensions (OR 1.27, 95\% CI 1.05-1.51), participation in quality network workshops increased the OR, as did reporting the QI plans for the coming year and participating in the advisory board meetings (table 3 ).
The random effect variation was higher for employers (municipalities) random effects than for yearly random effects for all the models. The standard deviations for random effect of employers were 0.415 (95\% CI 0.266 $0.628)$ in full permanent disability pension, $0.312(95 \%$ CI 0.197-0.480) in partial permanent disability pension, 0.251 (95\% CI $0.139-0.416)$ in full provisional disability pension, 0.551 (95\% CI $0.276-0.873)$ in partial provisional disability pension and $0.264(95 \%$ CI $0.172-0.400)$ in all disability pension together. The standard deviations for random effects of the study year were $0.241(95 \% \mathrm{CI}$ 0.119-0.426), 0.124 (95\% CI 0.037-0.247), 0.144 (95\% CI $0.072-0.25), 0.185$ (95\% CI $0.031-0.474$ ), and 0.116 (95\% CI 0.064-0.196), respectively. During the model selection process, covariates were dropped out from the model one at the time. Table 3 reports the OR for covariates included in the final models. DIC was used for

Table 3. The odds ratios (OR) with $95 \%$ credible intervals (Cl) for disability pensions of affiliation with the quality network and participation in quality improvement (QI) activities (covariates) of the occupational healthcare units. [OQN= Occupational Health Quality Network; QM=quality measurement; ns=the independent covariate has been excluded from the final model due to model selection.]

\begin{tabular}{|c|c|c|c|c|c|}
\hline Covariate & $\begin{array}{c}\text { Full permanent } \\
\text { disability pension } \\
\text { OR }(95 \% \mathrm{Cl})\end{array}$ & $\begin{array}{l}\text { Partial permanent } \\
\text { disability pension } \\
\text { OR }(95 \% \mathrm{CI})\end{array}$ & $\begin{array}{l}\text { Full provisional } \\
\text { disability pension } \\
\text { OR }(95 \% \mathrm{Cl})\end{array}$ & $\begin{array}{l}\text { Partial provisional } \\
\text { disability pension } \\
\text { OR }(95 \% \mathrm{Cl})\end{array}$ & $\begin{array}{l}\text { All disability } \\
\text { pensions } \\
\text { OR }(95 \% \mathrm{Cl})\end{array}$ \\
\hline Affiliation with the Finnish OQN & $0.77(0.60-0.98)$ & $0.82(0.58-1.13)$ & $0.68(0.53-0.87)$ & $2.42(1.41-3.84)$ & $0.86(0.72-1.03)$ \\
\hline \multicolumn{6}{|l|}{ Participation in } \\
\hline QM of intervening in excessive alcohol use & ns & $0.35(0.22-0.55)$ & $0.69(0.48-0.96)$ & $0.60(0.29-1.14)$ & $0.53(0.41-0.68)$ \\
\hline QM of health check-ups & ns & $0.74(0.57-0.95)$ & ns & $0.59(0.39-0.85)$ & $0.87(0.75-1.00)$ \\
\hline Quality facilitator training & ns & $0.92(0.78-1.07)$ & ns & ns & $0.92(0.84-0.99)$ \\
\hline Focus of work measurements & ns & $0.77(0.57-1.02)$ & ns & $1.21(0.75-1.85)$ & $0.84(0.71-0.98)$ \\
\hline Resource measurements & $0.77(0.53-1.11)$ & $1.36(0.99-1.83)$ & ns & ns & ns \\
\hline Quality network workshops & ns & $1.09(1.02-1.16)$ & $1.06(1.01-1.11)$ & $1.03(0.94-1.13)$ & $1.05(1.02-1.09)$ \\
\hline Peer review training & ns & $1.12(1.04-1.20)$ & ns & $1.05(0.93-1.18)$ & ns \\
\hline QM of depression care & ns & $1.40(0.99-1.91)$ & ns & $1.27(0.77-2.00)$ & $1.27(1.05-1.51)$ \\
\hline Advisory board of the quality network & ns & ns & $1.33(0.98-1.76)$ & $1.43(0.67-2.67)$ & $1.46(1.17-1.81)$ \\
\hline Employer \& employee satisfaction measurements & ns & ns & ns & ns & ns \\
\hline \multicolumn{6}{|l|}{ Reporting } \\
\hline Ql plans for the coming year & ns & $1.53(1.02-2.21)$ & ns & $2.11(1.13-3.65)$ & $1.34(1.09-1.62)$ \\
\hline Ql activities & ns & $1.30(0.86-1.87)$ & ns & ns & ns \\
\hline
\end{tabular}

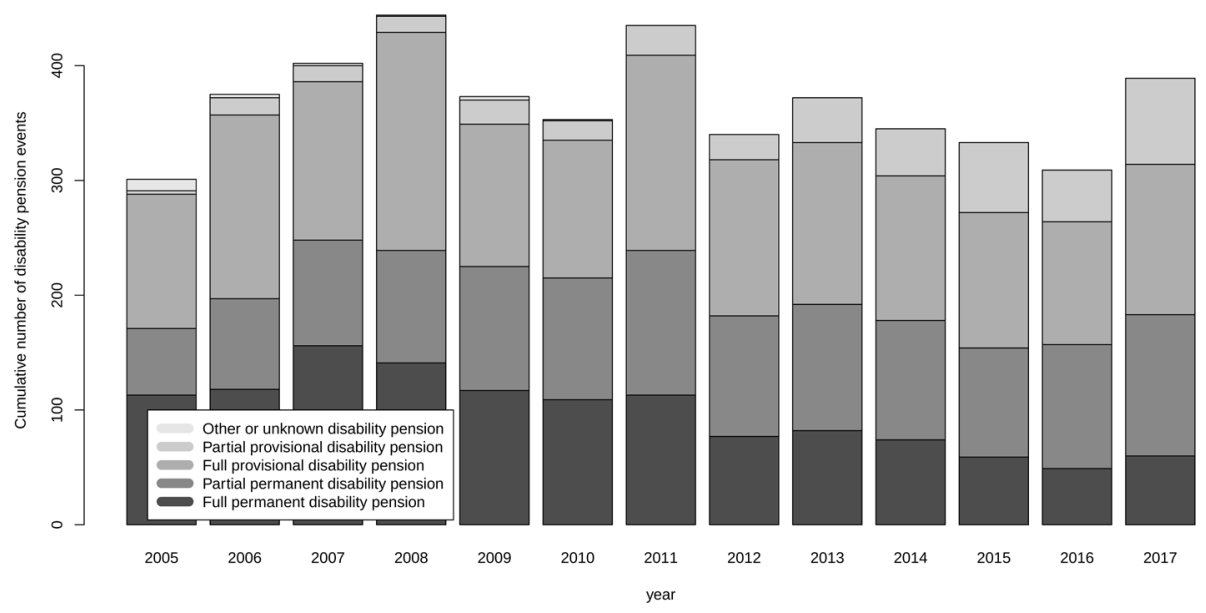

Figure 1. The cumulative number of different categories of granted disability pensions in the study population by year from 2005 to 2017 showing the development even before the study period 2011-2017. 
model selection and final values are 957.3, 970.3, 1052.5, 564.6 and 25746.4 , respectively.

\section{Discussion}

Our study showed that some QI activities had a positive association with the core outcome of $\mathrm{OHC}$, namely reduction of early disability retirement. We found several improvement activities that were positively associated with work ability but also such that had negative associations. The activities with the strongest positive association with the reduction of early disability retirement were, in the order of their strength, participation in: (i) the quality measurements of intervening in excessive use of alcohol, (ii) the focus of work measurements and (iii) the quality facilitator training.

The affiliation of the OHC unit with the OQN showed a risk reduction of full permanent disability pensions and full provisional disability pensions while partial disability pensions did not differ from the comparison group. These findings might show that some full disability pensions have been replaced with partial disability pensions. We think that the results showed a change towards the intended targets of the OQN, namely, a reduction of full permanent disability pensions and shift to partial disability pensions.

Shifts from full to partial disability benefits, even in short-term sickness absences, have been shown to increase long-term work participation (32) and to bring social security savings (33). The shift towards partial disability benefits can be a way to break a downward spiral pattern found by a Danish study, in which a previous sickness absence was associated with the increased risk of work disability pension through a transition cycle: from work to sickness absence, from sickness absence to unemployment or to a disability pension (34).

We demonstrated a reduction in the granted disability retirements. This positive result may have been driven by the sum of all the QI activities, although it seems that some improvement activities have stronger effects than others. Earlier studies on the reduction of the need for disability retirement have shown the importance of broad multi-domain activities in the workplace in collaboration with $\mathrm{OHC}(10,11)$. Such positive shifts often need multidisciplinary collaboration. In their systematic review, Cullen et al (8) showed that workplace-based return-to-work interventions and work disability management interventions helped workers with musculoskeletal and pain-related conditions and mental health conditions to return to work (8). The authors recommend that the interventions should include healthcare provision, service coordination and work accommodation components.
The QI activities affected the four disability pension types in different ways. The novel and surprising finding of this study was that participation in the quality measurements of intervening in excessive use of alcohol had such a strong association with the reduction of all disability pensions. One may speculate about the reasons why this activity was so effective. One explanation could be that healthcare workers find it difficult to discuss alcohol use. By participating in this activity, the management showed to the $\mathrm{OHC}$ personnel that intervening in risky use of alcohol is important. Studies have shown that excessive alcohol use is a strong driver of early retirement in Finland $(35,36)$. Screening, health advice and support to tackle alcohol-connected risk behavior are inexpensive especially when compared to disability retirement (37). There is also evidence that intervention at the workplace is effective in reducing problems related to excessive alcohol consumption (38).

Participation in the focus of work measurements, such as how diagnoses affect the patient flow, was associated with reductions in all types of disability pensions together. Such measurements can be difficult to make because the data are hard to find in patient and administrative records. The results regarding this activity may reflect this barrier and could show that units willing to perform the activity are also willing to make the necessary changes in patient flow.

The positive association we found concerning participation in the quality facilitator training was anticipated and could reflect the fact that deeper knowledge of the fundaments of QI may bring better results (39). Participation in the quality measurements of HCU had a weak association with the reduction in disability retirement. The reductions were mainly seen in the partial disability pensions. In Finland, $\mathrm{HCU}$ in $\mathrm{OHC}$ are targeted at employees who are in danger of prolonged sick leave and early retirement, those who are exposed to work hazards (such as chemicals and noise), and controls in 5- to 10-year intervals of the ageing. The first two types were the target group of our study. The associations we found may indicate that the activity has not led to major improvements in the processes that support work ability. However, some studies have found HCU to be a valuable component of Finnish OHC. The targeted HCU may work as triggers for interventions to address poor work ability $(9,40)$ while they can also work as interventions themselves (8). The health education given during HCU may have some effect in the prevention of occupational asthma and accidents (41). Moreover, health education may be even more important from the point of view that the risk factors found during $\mathrm{HCU}$ have predictive value of mortality for decades (20). On the other hand, while targeted HCU seem to be important, untargeted HCU in primary healthcare seem to have little or no effect on mortality or morbidity (42). 
It appears that participation in the quality measurements of depression care was associated with an increased risk of all disability pensions. This finding is somewhat surprising since one would expect this measurement activity to show comprehensive interest in the mental health of employees. The result may, however, indicate an excessive presence of mental problems and could reflect the findings of the systematic review of Cullen et al (8), which found that the traditional cognitive therapy methods used in OHC may be ineffective, and highlights the need for new work-focused cognitive behavioral interventions (8). Participation in quality network workshops, reporting the QI plans for the coming year, and participating in the advisory board meetings were also negatively associated with the reduction of disability pensions. It is important to recognize that not all changes result in improvement (4), but perhaps these activities do not have direct influence on the focus of work in the $\mathrm{OHC}$ unit.

The strengths of our study were that we were able to evaluate the association of several QI activities with the outcomes - ie, early disability retirement - and follow over a long period the main outcome of effective $\mathrm{OHC}$, namely the prevention of early retirement. It seems that Bayesian mixed-effect modelling can be a feasible method in assessing the effect of multiple QI activities in healthcare.

The study had also weaknesses. Only the common QI activities of the OQN were included in the study. Several improvement activities of OHC based only in one unit were not included in the study. We did not include the results of resource or process measurements in the analysis of this study because of their high number. The $\mathrm{OHC}$ units have also participated in them at different times. Other limitations of this study were that the OHC units affiliated with the OQN may have had better OHC practices and greater interest to QI than the non-affiliated units even before the study. This could affect the results per se.

It is possible that the results of our study are not generalizable to all $\mathrm{OHC}$ units, not even within Finland. However, the results show the direction for further studies.

\section{Concluding remarks}

This study showed that $\mathrm{OHC}$ units reduced the numbers of disability pensions when affiliated with the quality network. Moreover, participation in the quality measurements of intervening in excessive use of alcohol, quality facilitator training, and the focus of work measurements may decrease the risk of work disability pension among employees of companies in the care of $\mathrm{OHC}$ units participating in these activities.

\section{Acknowledgements}

We extend our thanks to Keva for providing the data for this study, and especially to Katinka Lybäck, Head of Statistics at Keva, for her important advice and data collection.

Jarmo Kuronen has received grants from the Finnish Cultural Foundation and from Niilo Helander Foundation.

\section{Conflicts of interest}

Jarmo Kuronen works in a participating OHC unit. Klas Winell owns a quality improvement company. Juho Kopra and Kimmo Räsänen declare no conflicts of interest.

The grants from the Finnish Cultural Foundation and from Niilo Helander Foundation did not affect the study protocol, data set-up or reporting in any ways.

\section{Ethical approval}

An ethical review statement from a human sciences ethical committee is not required in this particular study, which is based solely on public information, registry and documentary data (43).

\section{References}

1. Institute of Medicine (US) Committee on Quality of Health Care in America. Crossing the Quality Chasm: A New Health System for the 21st Century. Washington (DC): National Academies Press (US); 2018 Aug 28. ISBN-13: 978-0-30947789-5. Available from: https://www.ncbi.nlm.nih.gov/ books/NBK535657/\#sec_000030. [Accessed 17.3.2019].

2. Moraros J, Lemstra M, Nwankwo C. Lean interventions in healthcare: do they actually work? A systematic literature review. Int J Qual Health Care 2016 Apr;28(2):150-65. https://doi.org/10.1093/intqhe/mzv123.

3. Rotter T, Plishka C, Lawal A, Harrison L, Sari N, Goodridge D et al. What Is Lean Management in Health Care? Development of an Operational Definition for a Cochrane Systematic Review. Eval Health Prof 2019 Sep;42(3):36690. https://doi.org/10.1177/0163278718756992.

4. Benneyan JC, Lloyd RC, Plsek PE. Statistical process control as a tool for research and healthcare improvement. Qual Saf Health Care 2003 Dec;12(6):458-64. https://doi. org/10.1136/qhc.12.6.458.

5. Williams-Whitt K, Bültmann U, Amick B 3rd, Munir F, Tveito TH, Anema JR; Hopkinton Conference Working Group on Workplace Disability Prevention. Workplace Interventions to Prevent Disability from Both the Scientific and Practice Perspectives: A Comparison of Scientific Literature, Grey Literature and Stakeholder Observations. 
J Occup Rehabil 2016 Dec;26(4):417-33. https://doi org/10.1007/s10926-016-9664-z.

6. Oakman J, Neupane S, Proper KI, Kinsman N, Nygård $\mathrm{CH}$. Workplace interventions to improve work ability: A systematic review and meta-analysis of their effectiveness. Scand J Work Environ Health 2018 Mar;44(2):134-46. https://doi.org/10.5271/sjweh.3685.

7. Tompa E, Kalcevich C, Foley M, McLeod C, Hogg-Johnson $\mathrm{S}$, Cullen $\mathrm{K}$ et al. A systematic literature review of the effectiveness of occupational health and safety regulatory enforcement. Am J Ind Med 2016 Nov;59(11):919-33. https://doi.org/10.1002/ajim.22605.

8. Cullen KL, Irvin E, Collie A, Clay F, Gensby U, Jennings PA et al. Effectiveness of Workplace Interventions in Return-toWork for Musculoskeletal, Pain-Related and Mental Health Conditions: An Update of the Evidence and Messages for Practitioners. J Occup Rehabil 2018 Mar;28(1):1-15. https:// doi.org/10.1007/s10926-016-9690-x.

9. Taimela S, Aronen P, Malmivaara A, Sintonen H, Tiekso J, Aro T. Effectiveness of a targeted occupational health intervention in workers with high risk of sickness absence: baseline characteristics and adherence as effect modifying factors in a randomized controlled trial. J Occup Rehabil 2010 Mar;20(1):14-20. https://doi.org/10.1007/s10926-0099221-0.

10. Wickizer TM, Franklin GM, Fulton-Kehoe D. Innovations in Occupational Health Care Delivery Can Prevent Entry into Permanent Disability: 8-Year Follow-up of the Washington State Centers for Occupational Health and Education. Med Care 2018 Dec;56(12):1018-23. https://doi.org/10.1097/ MLR.0000000000000991.

11. Midtsundstad TI, Nielsen RA. Do workplace interventions reduce disability rates? Occup Med (Lond) 2016 Dec;66(9):691-7. https://doi.org/10.1093/occmed/kqw169.

12. Kuoppala J, Lamminpää A. Rehabilitation and work ability: a systematic literature review. J Rehabil Med 2008 Nov;40(10):796-804. https://doi.org/10.2340/165019770270 .

13. Vos T, Allen C, Arora M, Barber RM, Bhutta Z, Brown A et al.; GBD 2015 Disease and Injury Incidence and Prevalence Collaborators. Global, regional, and national incidence, prevalence, and years lived with disability for 310 diseases and injuries, 1990-2015: a systematic analysis for the Global Burden of Disease Study 2015. Lancet 2016 Oct;388(10053):1545-602. https://doi.org/10.1016/S01406736(16)31678-6.

14. Honkonen TI, Aro TA, Isometsä ET, Virtanen EM, Katila HO. Quality of treatment and disability compensation in depression: comparison of 2 nationally representative samples with a 10-year interval in Finland. J Clin Psychiatry 2007 Dec;68(12):1886-93. https://doi.org/10.4088/JCP. v68n1208.

15. Theis KA, Roblin DW, Helmick CG, Luo R. Prevalence and causes of work disability among working-age U.S. adults, 2011-2013, NHIS. Disabil Health J 2018 Jan;11(1):108-15. https://doi.org/10.1016/j.dhjo.2017.04.010.
16. Rechel B, Grundy E, Robine JM, Cylus J, Mackenbach JP, Knai $\mathrm{C}$ et al. Ageing in the European Union. Lancet 2013 Apr;381(9874):1312-22. https://doi.org/10.1016/S01406736(12)62087-X.

17. Poscia A, Moscato U, La Milia DI, Milovanovic S, Stojanovic J, Borghini A et al. Workplace health promotion for older workers: a systematic literature review. BMC Health Serv Res 2016 Sep;16 Suppl 5:329. https:/doi. org/10.1186/s12913-016-1518-z.

18. Airaksinen J, Jokela M, Virtanen M, Oksanen T, Pentti $\mathrm{J}$, Vahtera $\mathrm{J}$ et al. Development and validation of a risk prediction model for work disability: multicohort study [Erratum in: Sci Rep. 2018;1:17224]. Sci Rep 2017 Oct;7(1):13578. PubMed https://doi.org/10.1038/s41598017-13892-1

19. Brook RH, McGlynn EA, Cleary PD. Quality of health care. Part 2: measuring quality of care. N Engl J Med 1996 Sep;335(13):966-70. https://doi.org/10.1056/ NEJM199609263351311.

20. Bjerkedal T, Kristensen P, Selmer R. Life expectancy and cause of death in men examined at medical check-ups in 1964. Tidsskr Nor Laegeforen 2012 Jan;132(1):30-5. https:// doi.org/10.4045/tidsskr.11.0506.

21. Lazar EJ, Fleischut P, Regan BK. Quality measurement in healthcare. Annu Rev Med 2013;64:485-96. https://doi. org/10.1146/annurev-med-061511-135544.

22. Rubin HR, Pronovost P, Diette GB. The advantages and disadvantages of process-based measures of health care quality. Int J Qual Health Care 2001 Dec;13(6):469-74. https://doi.org/10.1093/intqhe/13.6.469.

23. Hamberg-van Reenen HH, Proper KI, van den Berg M. Worksite mental health interventions: a systematic review of economic evaluations. Occup Environ Med 2012 Nov;69(11):837-45. https://doi.org/10.1136/ oemed-2012-100668.

24. Brown BB, Patel C, McInnes E, Mays N, Young J, Haines $M$. The effectiveness of clinical networks in improving quality of care and patient outcomes: a systematic review of quantitative and qualitative studies. BMC Health Serv Res 2016 Aug;16:360. https://doi.org/10.1186/s12913-0161615-z.

25. Laffel G, Blumenthal D. The case for using industrial quality management science in health care organizations. JAMA 1989 Nov;262(20):2869-73. https://doi.org/10.1001/ jama.1989.03430200113036.

26. McCulloch C, Neuhaus J. Generalized Linear Mixed Models. In Encyclopedia of Biostatistics (Editors P. Armitage and T. Colton). https://doi.org/10.1002/0470011815.b2a10021.

27. Plummer M. JAGS: A program for analysis of Bayesian graphical models using Gibbs sampling. In Proceedings of DSC. 2003; (Vol. 2, No. 1). Available from: http://www. ci.tuwien.ac.at/Conferences/DSC-2003/Drafts/Plummer.pdf

28. R Core Team. R: A language and environment for statistical computing. R Foundation for Statistical Computing, Vienna, Austria. 2019. Available from: https://www.R-project.org/. 
29. Robert C, Casella G. Monte Carlo statistical methods. Springer Science \& Business Media, 2013. ISBN 978-1-47573071-5 (eBooks).

30. Brooks S, Gelman A. General methods for monitoring convergence of iterative simulations. J Comput Graph Stat 1997;7:434-55.

31. Spiegelhalter D, Best N, Carlin B, Van Der Linde A. Bayesian measures of model complexity and fit. J R Stat Soc Series B Stat Methodol 2002;64(4):583-639. https://doi. org/10.1111/1467-9868.00353.

32. Viikari-Juntura E, Virta LJ, Kausto J, Autti-Rämö I, Martimo $\mathrm{KP}$, Laaksonen $\mathrm{M}$ et al. Legislative change enabling use of early part-time sick leave enhanced return to work and work participation in Finland. Scand J Work Environ Health 2017 Sep;43(5):447-56. https://doi.org/10.5271/sjweh.3664.

33. Viikari-Juntura E, Leinonen T, Virta LJ, Hiljanen I, Husgafvel-Pursiainen K, Autti-Rämö I et al. Early parttime sick leave results in considerable savings in social security costs at national level: an analysis based on a quasiexperiment in Finland. Scand J Work Environ Health 2019 Mar;45(2):203-8. https://doi.org/10.5271/sjweh.3780.

34. Pedersen J, Bjorner JB, Burr H, Christensen KB. Transitions between sickness absence, work, unemployment, and disability in Denmark 2004-2008. Scand J Work Environ Health 2012 Nov;38(6):516-26. https://doi.org/10.5271/ sjweh.3293.

35. Salonsalmi A, Laaksonen M, Lahelma E, Rahkonen O. Drinking habits and disability retirement. Addiction 2012 Dec;107(12):2128-36. https://doi.org/10.1111/j.13600443.2012.03976.x.

36. Hannu T, Lahti J, Lahelma E, Rahkonen O. Do differences in risk factors for partial and full disability pensions exist? A prospective cohort study among employees of the city of Helsinki [In Finnish, summary in English]. SLL 2016;4:236-43.

37. Khadjesari Z, Newbury-Birch D, Murray E, Shenker D, Marston L, Kaner E. Online health check for reducing alcohol intake among employees: a feasibility study in six workplaces across England. PLoS One 2015 Mar;10(3):e0121174. https:// doi.org/10.1371/journal.pone.0121174.
38. Yuvaraj K, Eliyas SK, Gokul S, Manikandanesan S. Effectiveness of Workplace Intervention for Reducing Alcohol Consumption: a Systematic Review and MetaAnalysis. Alcohol Alcohol 2019 May;54(3):264-71. https:// doi.org/10.1093/alcalc/agz024.

39. Botje D, Ten Asbroek G, Plochg T, Anema H, Kringos DS, Fischer $\mathrm{C}$ et al. Are performance indicators used for hospital quality management: a qualitative interview study amongst health professionals and quality managers in The Netherlands. BMC Health Serv Res 2016 Oct;16(1):574. https://doi.org/10.1186/s12913-016-1826-3.

40. Piha K, Sumanen H, Lahelma E, Rahkonen O. Socioeconomic differences in health check-ups and medically certified sickness absence: a 10-year follow-up among middle-aged municipal employees in Finland. J Epidemiol Community Health 2017 Apr;71(4):390-5. https://doi.org/10.1136/jech2016-208185.

41. Schaafsma FG, Mahmud N, Reneman MF, Fassier JB, Jungbauer FH. Pre-employment examinations for preventing injury, disease and sick leave in workers. Cochrane Database Syst Rev 2016 Jan;1(1):CD008881. https://doi.org/10.1002/14651858.CD008881.pub2.

42. Krogsbøll LT, Jørgensen KJ, Gøtzsche PC. General health checks in adults for reducing morbidity and mortality from disease. Cochrane Database Syst Rev 2019 Jan;1(1):CD009009. https://doi.org/10.1002/14651858. CD009009.pub3.

43. Kohonen I, Kuula-Luumi A, Spoof SK. The ethical principles of research with human participants and ethical review in the human sciences in Finland. Publications of the Finnish National Board on Research Integrity TENK 3/2019: 62. Available from: https://www.tenk.fi/sites/tenk.fi/files/ Ihmistieteiden_eettisen_ennakkoarvioinnin_ohje_2019.pdf.

Received for publication: 18 September 2019 